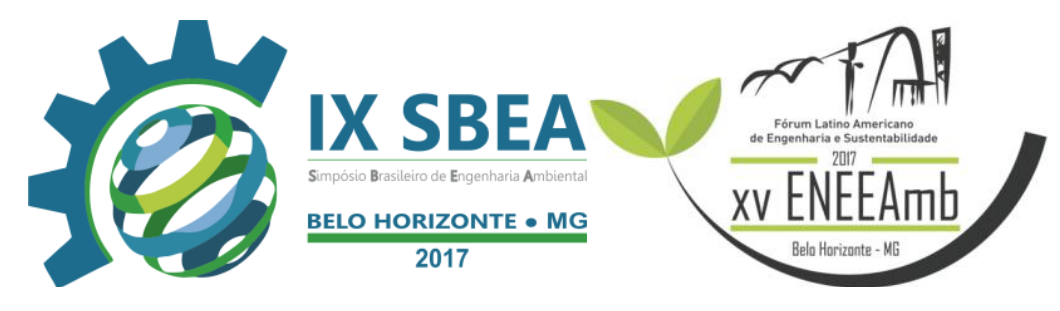

\author{
ÁREA TEMÁTICA: \\ RECURSOS HÍDRICOS E SANEAMENTO
}

TÍTULO DO TRABALHO:

\title{
EFICIÊNCIA DE DESINFECÇÃO DE ÁGUAS RESIDUAIS POR RADIAÇÃO UV E POR OZÔNIO NA ETAR DE SETÚBAL (PORTUGAL)
}

Maria Fernanda de Azevedo Soares - m.fernanda_@ hotmail.com Universidade Federal de Juiz de Fora

Ana Carolina Nascimento Leão - anacleao@outlook.com

Universidade Federal de Juiz de Fora

Ricardo Manuel Nunes Salgado - ricardo.salgado@estsetubal.ips.pt

Instituto Politécnico de Setúbal 


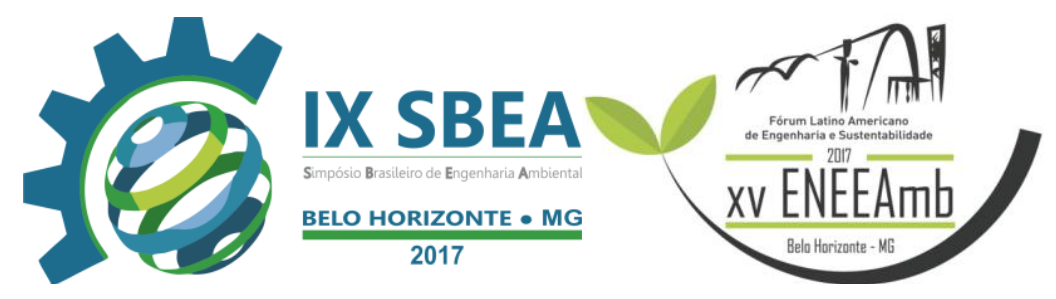

\section{RESUMO}

As águas residuais são caracterizadas por conterem uma quantidade elevada de organismos patogênicos, que mesmo após o tratamento secundário ainda se encontram presentes, assim é preciso fazer o processo de desinfecção, pois esses são prejudiciais à saúde humana e aos corpos receptores. Esse processo pode ser principalmente por Cloro, UV e Ozônio sendo o objetivo desse trabalho comparar os três métodos através da metodologia do Número Mais Provável (NMP) e utilizando a Lei de Chick. Nos resultados obtidos foi possível perceber que todas as amostras após a desinfecção continham Coliformes Totais, mas nenhuma, Coliformes Fecais e consequentemente E.Coli. Todas as amostras se enquadravam na legislação portuguesa e na brasileira. Na desinfecção por Cloro e UV se obteve 99,99\% de desinfecção enquanto que por ozônio 73,28\%. Foi possível concluir que a desinfecção por Cloro apresenta um melhor benefício se comparada com as demais, uma vez que o efluente é corado o que não favorece a desinfecção por UV.

Palavras chaves: Tratamento de águas residuais, desinfecção por cloro, UV, Ozônio, desinfecção.

\section{INTRODUÇÃO/OBJETIVO}

A sociedade tecnológica atual, fruto do desenvolvimento acelerado e demanda de recursos, possui a difícil missão de gerir as emissões secundárias dos seus processos. Dentre essas emissões, as chamadas águas residuárias podem ser definidas como a combinação de efluentes líquidos e rejeitos arrastados pela água. Geralmente são classificados em dois grandes grupos: os efluentes sanitários e os industriais. (JORDÃO; PESSÔA, 2009; METCALF; EDDIE, 2004; SPERLING, 2005).

As águas residuais são caracterizadas por conterem uma quantidade elevada de organismos patogênicos, como coliformes totais, fecais, E. coli e os ovos de parasitas intestinais o que pode ser prejudicial para o corpo receptor e gerar diversos impactos para o meio ambiente, como o risco de propagação de doenças infectocontagiosas. Dessa forma, torna-se essencial a eliminação desses agentes na água, sendo esse um dos objetivos do tratamento de águas residuais.

As tecnologias de tratamento utilizadas nos processos de desinfecção incluem tratamentos físicos como o uso de radiação ultravioleta com lâmpadas de baixa pressão 


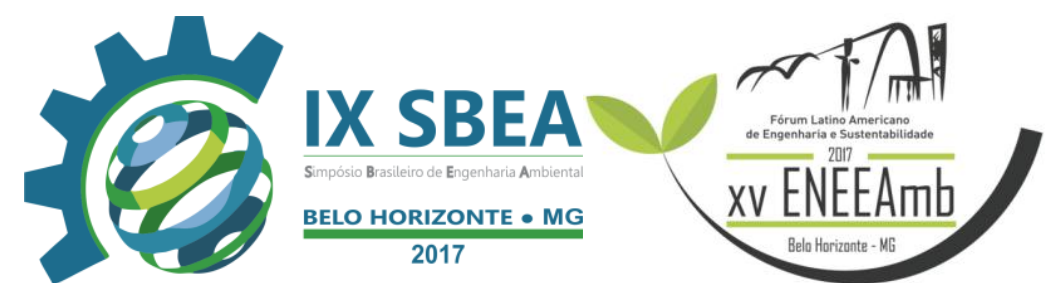

monocromáticas ou de média pressão policromáticas e tratamentos químicos como o uso de ozônio e cloro. Os fatores que influenciam a escolha do processo mais adequado são: a natureza da água e concentração do agente desinfetante, o tempo de contato, temperatura, número e tipo de microorganismos presentes e qualidade da água a ser desinfetada (LAPOLLI, 2005)

Além disso, as legislações são importantes ferramentas que estabelecem limites dos agentes patogênicos existentes na água residual. Para diminuição do impacto da descarga das águas residuais em rios ou estuários e a possibilidade de reutilizar a água residual tratada para rega de jardins e lavagem de ruas, a legislação portuguesa, no Decreto-lei n. ${ }^{\circ}$ 236/98 de $1^{\circ}$ de agosto prevê no Anexo I os valores VMR e VMA. O valor VMR de referência de coliformes fecais é de 100/100 mL e VMA de ovos de parasitas intestinais é de 1/L. Já a legislação brasileira o limite permitido para a mesma função já mencionada é de 200 coliformes termotolerantes por $100 \mathrm{ml}$ de acordo com a CONAMA (Conselho Nacional do Meio ambiente) 357/2005.

Em Portugal a tecnologia mais utilizada no tratamento de águas residuais é a desinfecção por UV enquanto que no Brasil utilizam-se mais a desinfecção por cloração. Nesse trabalho, falaremos de três processos de desinfecção: radiação UV de média pressão, cloração e com ozônio.

\subsection{OBJETIVO}

Este trabalho teve como objetivo avaliar a eficiência da desinfecção por cloro na ETAR de Setúbal e realizar experiências em laboratorio com radiação UV e ozônio para comparar a eficiência de remoção da desinfecção. Foram estudas as cinéticas de remoção de microrganismos por radiação UV e ozônio. Foi avaliado também o efeito da matriz da água residual para a aplicação da técnica de desinfecção por radiação UV/MP. A avaliação da eficiência foi realizada usando o método do Número Mais Provável (NMP) e empregando como microrganismos indicadores Coliformes Totais (CT), fecais e Escherichia coli

\section{METODOLOGIA}

\subsection{Descrição do sistema}




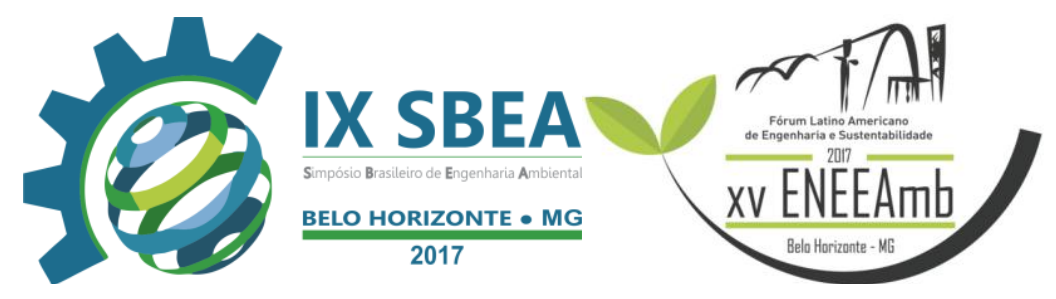

Este é um trabalho experimental que foi desenvolvido no Laboratório do curso de Engenharia do Ambiente, situado na Escola Superior de Tecnologia de Setúbal do Instituto Politécnico de Setúbal, Portugal. As amostras foram coletadas da Estação de Tratamento de Águas Residuais (ETAR) de Setubal que faz parte do Sistemas de Abastecimento de Água e de Saneamento das Águas do Sado. A estação atende uma população equivalente de 253.107 habitantes e possui uma capacidade de tratamento de $27.922 \mathrm{~m}^{3} /$ dia, sendo que $56 \%$ desse total representam a componente industrial.

\subsection{Coleta das amostras}

Foram coletadas quatro amostras de, sendo duas a montante do processo de desinfecção (2L)e duas a jusante da desinfecção (1L) realizada pela ETAR de Setúbal. As amostras foram colocadas imediatamente em uma recipiente térmicorefrigerado a $+4^{\circ} \mathrm{Ce}$ levadas ao laboratório

\subsection{Experiência radiação uv de média pressão (uv/mp)}

A lâmpada UV(Heraeus TQ Noblelight;150 W) utilizada na desinfecção foi uma lâmpada de vapor de mercúrio(Hg) UV de média pressão (MP).Essa emite uma radiação entre 200 e $600 \mathrm{~nm}$.

Foi colocada uma amostra de $700 \mathrm{~mL}$ de água residual efluente, coletada antes de desinfeção na ETAR,no reator. Foram recolhidas amostras de $5 \mathrm{~mL}$ de 2 em 2 minutos, sendo o tempo máximo de exposição ao UV de 12 minutos, totalizando assim 6 medições-Cada amostra recolhida foi distribuída em 3 tubos de ensaio com triptona sal para realizar as diluições da amostra para os ensaios de microbiologia. Foram realizadas as diluições da amostra tal e qual, $10^{-1}$ e $10^{-2}$.

A lâmpada foi colocada no centro do reator, no interior de uma camisa de arrefecimento que era feita de quartzo e refrigerada com água pura a passar continuamente na camisa. Esse sistema permitiu controlar a temperatura da lâmpada $\left(25^{\circ} \mathrm{C}\right)$ e filtrar a luz emitida.

\subsection{Experiência com ozônio}

O princípio utilizado é o do ozonizador (Electronic Ozonizer; Hailea; HLO$820 \mathrm{~A} ; 0,04 \mathrm{mg} / \mathrm{L} \mathrm{O}_{3}$ ).O equipamento foi acoplado a uma proveta de $1000 \mathrm{~mL}$, no sistema existiam dois frascos lavadores de gases ambos com solução de iodeto de potássio ligados a um fluxo de água que permitia fazer o vácuo nos frasco lavadores e 


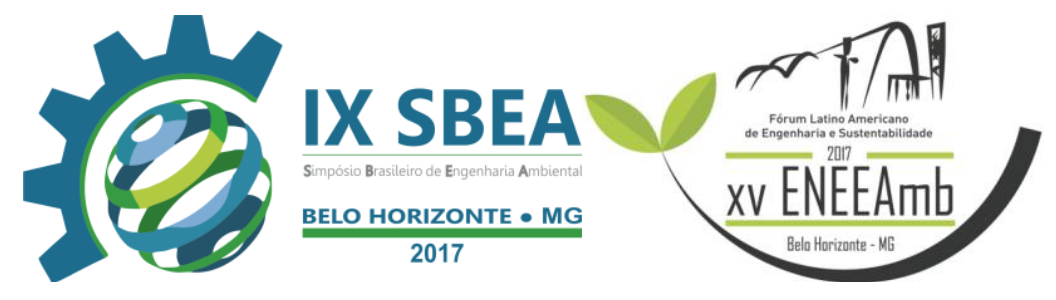

assim possibilitar que o ozônio fosse introduzido nas soluções de $\mathrm{KCl}$ saturada e não escapasse para o meio ambiente, ficando dissolvido.

O procedimento foi mantido isolado e realizado na hotte, por questões de segurança, uma vez que o ozônio é tóxico. Foi colocada uma amostra de $700 \mathrm{~mL}$ de água residual em uma proveta de $1000 \mathrm{~mL}$ (reator). Amostras de $5 \mathrm{~mL}$ foram recolhidas de 2 em 2 minutos sendo o tempo máximo de exposição ao Ozônio de 12 minutos, totalizando assim 6 medições. Foi retirado $5 \mathrm{ml}$ de 2 em 2 minutos sendo que $1 \mathrm{ml}$ foi para cada tubo,todas através de uma seringa descartável. Cada amostra recolhida foi distribuída em 3 tubos de ensaio com triptona sal para realizar as diluições da amostra para os ensaios de microbiologia. Foram realizadas as diluições da amostra tal e qual, $10^{-1}$ e $10^{-2}$

Para a determinação da concentração de Ozônio foi utilizado o Palinest Ozone teste que usa o método DPD (diethyl-p-phenylene diamine). O ozono reage com (DPD) em solução tampão, na presença de iodeto de potássio para produzir uma intensidade de cor. A cor rosa é proporcional à concentração de ozônio e é medida utilizando um Fotômetro Palintest.

Assim, em um tubo contendo um pouco da amostra de água residual após a desinfecção de 12 minutos com o ozônio foi acrescentado o comprimido de DPD que foi triturado até se dissolver por inteiro, em seguida completou-se com a amostra o tubo até se atingir $10 \mathrm{~mL}$. Por fim, selecionou-se o comprimento de onda de $520 \mathrm{~nm}$ no aparelho e colocou a amostra, com o resultado obtido no aparelho é possivel fazer a leitura do valor da concentração de ozônio residual em mg/L de $\mathrm{O}_{3}$.

\subsection{Determinações analíticas}

\subsubsection{Varrimento no espectrofotômetro}

O varrimento no espectrofotômetro foi realizado para a amostra não desinfetada e para as amostras desinfetadas por cloro, por UV e por $\mathrm{O}_{3}$. Essa foi realizada no espectro (ThermoScientific; Evolution 160 UV-VIS). Essas foram colocadas em célula de quartzo com $1 \mathrm{~cm}$ de percurso ótico e o varrimento feito de $190 \mathrm{~nm}$ a $400 \mathrm{~nm}$.

\subsubsection{Análises microbiológicas}




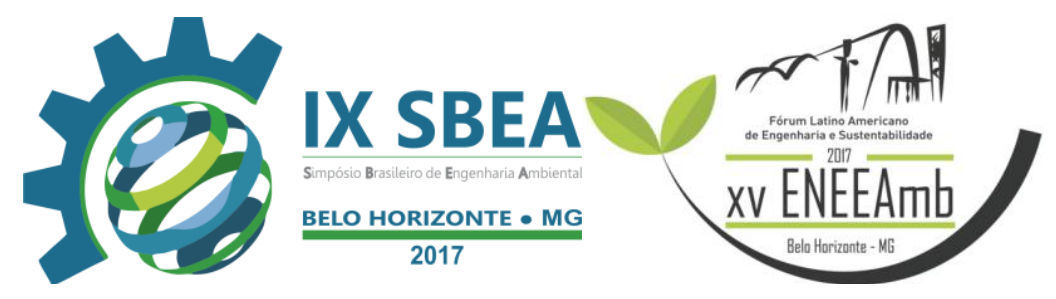

Após a preparação dos meios, água triptonada e verdes brilhantes (respeitando as instruções do fabricante) foram realizadas análises microbiológicas às amostras antes e depois do sistema de desinfecção com cloro, das experiências com radiação UV/MP e ozônio no laboratório pelo método NMP para a determinação de bactérias: Coliformes totais, fecais e Escherichia coli (E. coli). Para a realização das análises microbiológicas de CT e CF foram realizadas diluições com a solução de triptona sal, para a amostra tal e qual, a amostra diluída $10^{-1}$ e a amostra diluída a $10^{-2}$.

\subsubsection{Coliformes Totais}

Primeiramente foi medido $1 \mathrm{~mL}$ de amostra para cada um dos 5 tubos contando $10 \mathrm{~mL}$ de verde brilhante, depois mediu-se $1 \mathrm{~mL}$ da diluição $10^{-1}$ para cada um dos 5 tubos contendo $10 \mathrm{~mL}$ de verde brilhante e por fim, mediu-se $1 \mathrm{~mL}$ da diluição $10^{-2}$ para cada um dos 5 tubos contando $10 \mathrm{~mL}$ de de verde brilhante. Assim, para a verificação da existência de CT os tubos foram levados à incubação $\left(37^{\circ} \mathrm{C}, 48\right.$ horas) (Trade Raypa). Consideramos positivos os tubos que se apresentaram turvos e/ou com produção de gás.

\subsubsection{Coliformes fecais}

Para a análise dos coliformes fecais, consideramos os tubos positivos do teste para CT como potencias para a existência de coliformes fecais. Assim, foi retirada uma quantidade desses tubos com uma ansa esterilizada, o inoculo do tudo se apresentava previamente homogeneizado então, passamos para um novo tubo com o verde brilhante. A incubação foi feita a $44^{\circ} \mathrm{C}$ e durante 48 horas (Penterm; ES-6).Consideramos positivos os tubos que se apresentaram turvos e/ou com produção de gás.

\subsubsection{E.Coli}

Para a análise da existência de E.Coli, considerou-se potencial os tubos positivos para CT. Para isso, é necessário retirar com uma ansa esterilizada, o inoculo do tubo previamente homogeneizado e passar para um novo tubo com água triptonada. A incubação deve ser feita a $44^{\circ} \mathrm{C}$ durante 48 horas. Devem-se adicionar também algumas gotas do reagente de Kovacs, homogeneizar e esperar de 1 a 2 minutos. O resultado é considerado positivo se houver produção de indol que é representada pela formação de um anel rosa forte na parte superior do tubo.

\subsubsection{Determinação do NMP}




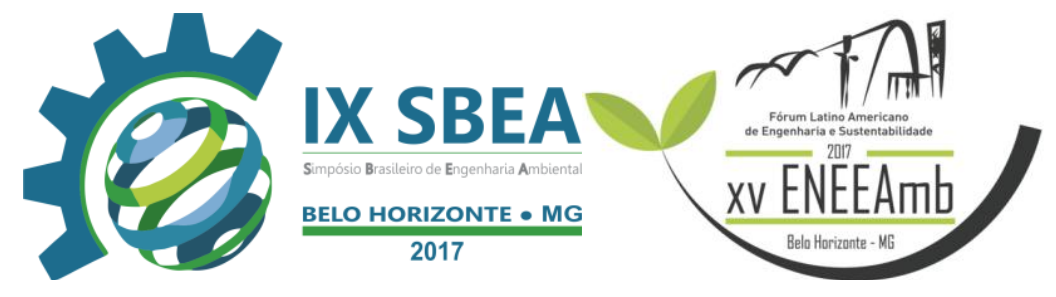

Para a determinação do NMP foi necessário escolher uma combinação de tubos positivos, correspondentes a 3 diluições consecutivas, considerando que o número de código tem 3 dígitos, sendo cada um, o número total de tubos positivos em cada diluição e por ordem decrescente de volume de inoculo. Assim através da tabela encontra-se o NMP corresponde ao código de 3 dígitos.

Esse cálculo da densidade de bactérias do grupo testado é baseado no número de tubos positivos de cada diluição. O resultado é dado com limite de $95 \%$ de confidência. Para o cálculo do NMP, para $100 \mathrm{~mL}$ da amostra, utiliza-se a Equação 1:

$$
N=N M P x \frac{10}{V} x f
$$

N - Número Mais Provável por $100 \mathrm{~mL}$

NMP - Valor lido na tabela

$\mathrm{V}-$ Volume de amostra $(\mathrm{mL})$

$\mathrm{f}$ - Fator de diluição

\section{RESULTADOS E DISCUSSÃO}

\subsection{Comparação da eficiência global desinfecção com cloro, radiação UV e ozônio}

A Tabela 1 mostra a eficiência global no processo de desinfecção da água residual. A desinfecção por cloro e por UV apresentaram melhores resultado (99,99\% de remoção de coliformes totais) que a desinfecção por Ozônio $(73,28 \%)$. Isso pode ter acontecido uma vez que se utilizou uma dose baixa de ozônio de 0,04 mg/L de $\mathrm{O}_{3}$ para um tempo de contato de 12 minutos.

Tabela 1: Comparação da eficiência global da desinfecção

\begin{tabular}{|c|c|c|c|}
\hline \multicolumn{4}{|c|}{ Comparação da eficiência global da desinfecção } \\
\hline & $\begin{array}{c}\text { Antes da desinfecção } \\
\text { (NMP/100 mL) }\end{array}$ & $\begin{array}{c}\text { Depois da desinfecção } \\
(\mathrm{NMP} / 100 \mathrm{~mL})\end{array}$ & \%Remoção \\
\hline Cloro & $1,6 \mathrm{E}+06$ & $2,0 \mathrm{E}+02$ & $99,99 \%(20 \mathrm{~min} ; 20 \mathrm{mg} / \mathrm{L} \mathrm{Cl}$ ) \\
\hline UV & $1,6 \mathrm{E}+06$ & $2,0 \mathrm{E}+02$ & $99,99 \%(6 \mathrm{~min} ; \mathrm{MP} / 150 \mathrm{~W})$ \\
\hline Ozônio & $1,6 \mathrm{E}+06$ & $1,6 \mathrm{E}+06$ & $73,28 \%\left(12 \mathrm{~min} ; 0,04 \mathrm{mg} / \mathrm{L} \mathrm{O} \mathrm{O}_{3}\right)$ \\
\hline
\end{tabular}

Já a desinfecção com UV teve uma remoção considerável, porém melhores resultados poderiam ser obtidos caso a ETAR não recebesse efluentes industriais com 


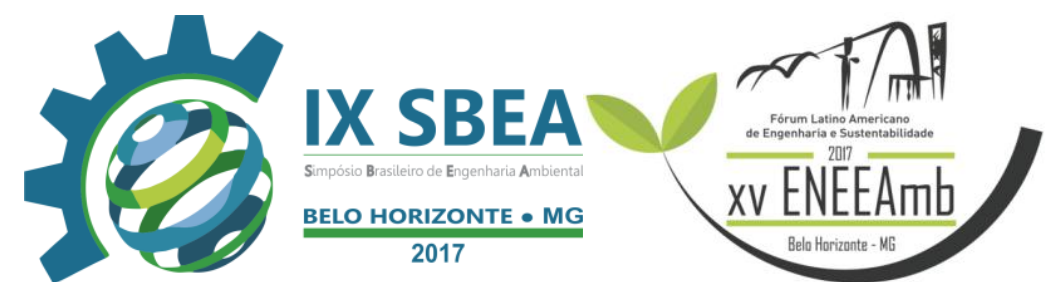

cor. Além disso, o tempo de contato com a lâmpada UV/MP para a remoção foi de 6 minutos enquanto que o tempo usual em uma ETAR para a remoção com lâmpadas UV/BP é de 1 minuto.

Por fim, a remoção por Cloro utilizada na ETAR, teve também uma remoção considerável e um melhor custo benefício comparada com as outras apesar de necessitar um tempo de contato maior que a lâmpada UV essa é mais vantajosa.

\subsection{Cinética de desinfecção com radiação UV e Ozônio}

A Figura 1 representa a cinética de desinfecção comparando a radiação UV com o Ozônio para remoção dos CT, e como é possível perceber a concentração desses caiu mais e mais rapidamente na desinfecção por UV.

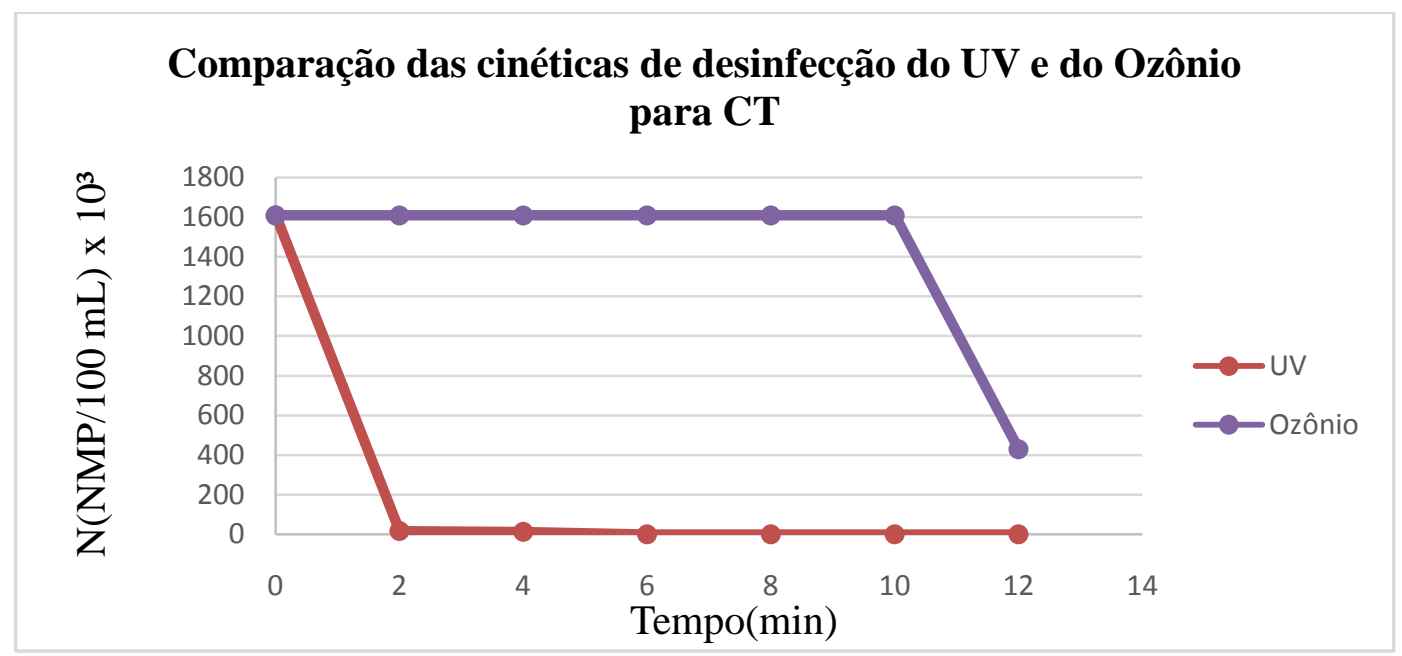

Figura 1: Comparação das cinéticas de desinfecção do UV e do Ozônio para CT

Não foi preciso fazer a cinética de desinfecção para os $\mathrm{CF}$, uma vez que não foi obtido nenhum resultado positivo tanto para o UV, quanto para o Ozônio após a segunda incubação, ou seja, não havia a presença desses após a desinfecção. Consequentemente não havia E.coli presente na água residual.

A partir dos dados obtidos e com base em um preceito importante para a cinética da desinfecção enunciada por Chick em 1908, e hoje conhecida como Lei de Chick foi possível concluir que a inativação dos microrganismos em função do tempo obedece ao modelo de uma reação de primeira ordem, Equação 2: 


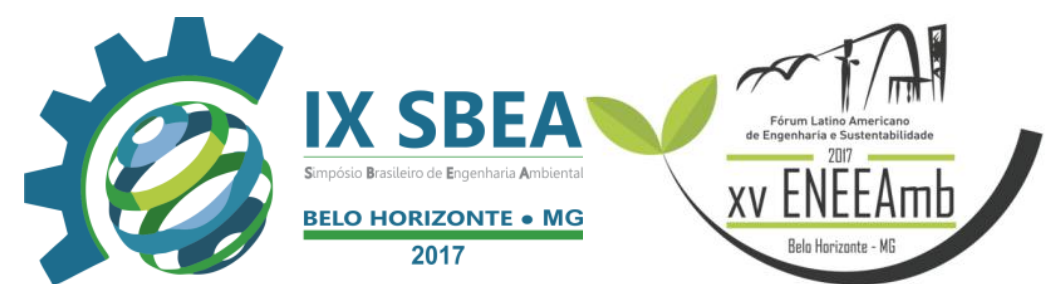

$$
-\frac{\delta N}{\delta t}=k d x N
$$

A equação fornece a velocidade de decaimento dos organismos em função da multiplicação do coeficiente de reação e tempo, T

Assim, obtivemos os valores do coeficiente de desinfecção dos microrganismos (Kd), de -0,5916 $\left(\mathrm{min}^{-1)}\right.$ para o UV e -0,0236( $\mathrm{min}^{-1)}$, para o Ozônio. O qual pode ressaltar que quanto maior o coeficiente, no caso o do UV mais rápida a remoção ocorre e quando menor o $\mathrm{Kd}$, mais lenta.

\subsection{Efeito da matriz na aplicação da radiação UV/MP}

Foi determinado o espectro de absorvância das amostras estudadas (Figura 2), após a desinfecção, que permite avaliar a presença de compostos orgânicos que dão cor à água e que absorvem a determinados comprimentos de onda da radiação UV-Visível.

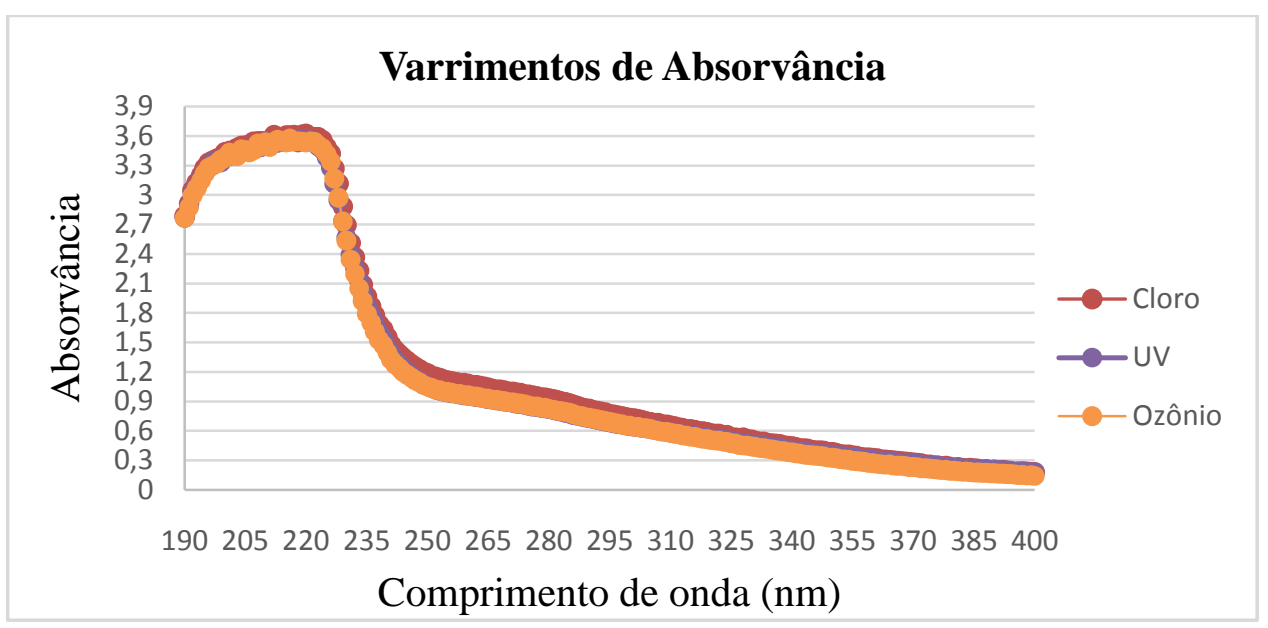

Figura 2: Varrimentos da absorvância em relação ao comprimento de onda para o cloro, UV e ozônio

Há grandes variações, ou seja, elas possuem características semelhantes de absorverem a radiação em frequências semelhantes. Além disso, representam que as concentrações das substâncias nelas contidas não diferem muito umas das outras.

Para que se tenha uma remoção eficiente através da utilização da lâmpada UV é necessário que se tenha pelo menos uma transmitância em $60 \%$ no comprimento de onda de $254 \mathrm{~nm}$. Entretanto, o que se verifica na Figura 3, essa é próxima a 10\% para 


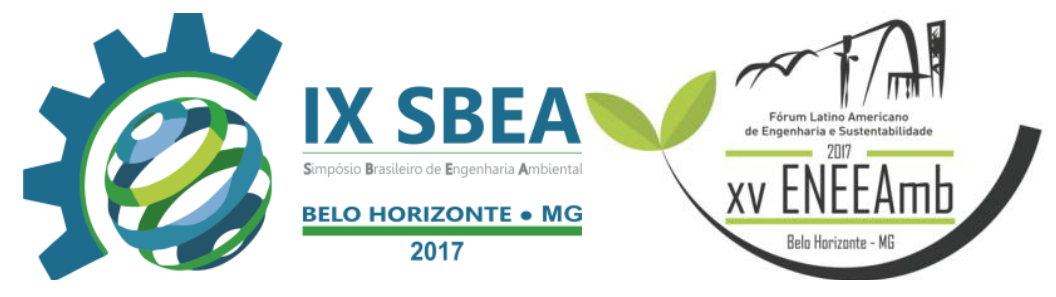

esse comprimento de onda. Portanto, a água absorve mais radiação e assim ocorre flutuação na desinfecção, contudo a remoção foi eficiente o que pode ser justificado pelo fato de que as lâmpadas utilizadas em laboratório serem de média pressão(MP) e assim mais eficientes que aquelas utilizadas em uma ETAR que são normalmente de baixa pressão(BP).

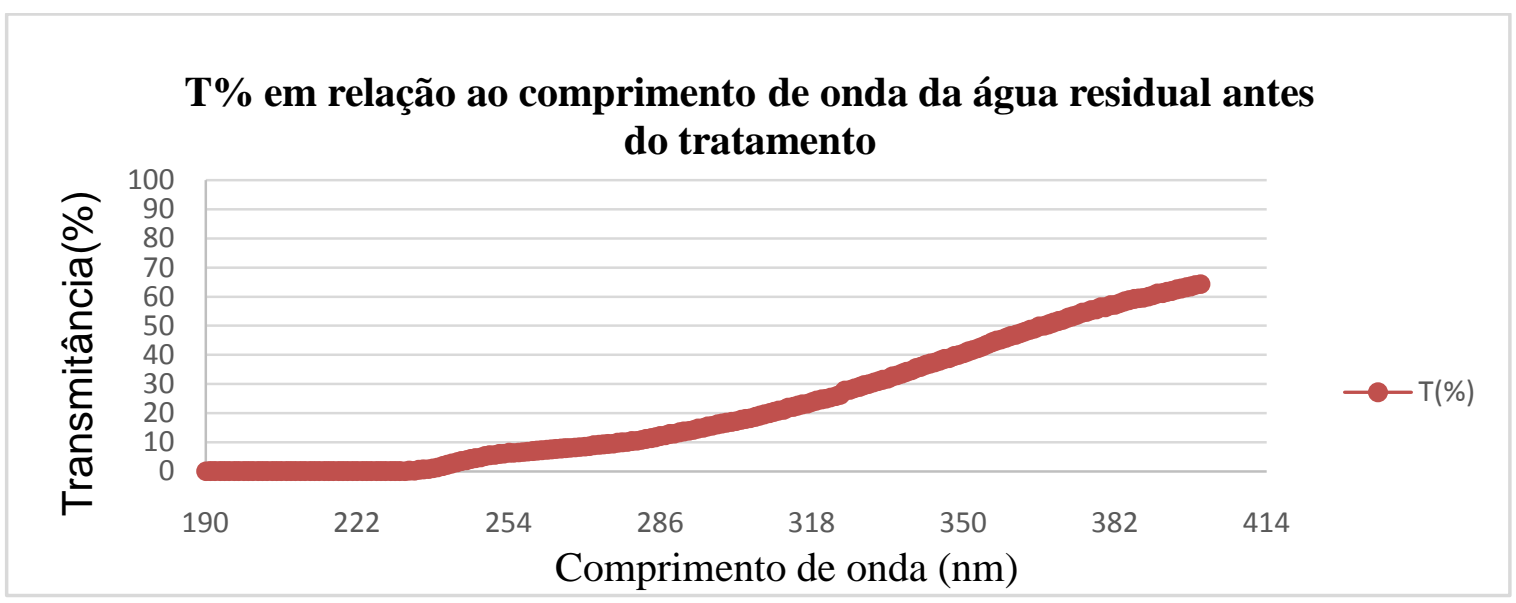

Figura 3: Transmitância em relação ao comprimento de onda da água residual antes do tratamento

\section{CONCLUSÕES/RECOMENDAÇÕES}

Tendo como base os estudos realizados, pode se concluir que as características do efluente da ETAR de Setúbal não são ideais para a utilização de desinfecção por UV, uma vez que o efluente apresenta cor e isso dificulta a penetração da luz impedindo assim a remoção dos microrganismos. O ideal para a utilização desse método é que se obtenha uma transmitância de pelo menos $60 \%$ a $254 \mathrm{~nm}$ e a obtida foi de $10 \%$.

Apesar da porcentagem de remoção ter sido de 99,99\% para o UV, a relação custo benefício não é boa, uma vez que o tempo de contato foi de 6 minutos e utilizaram-se lâmpadas de média pressão e em uma ETAR por questões de custos e tempo, utilizam-se lâmpadas de baixa pressão e o tempo de desinfecção é normalmente de 1 minuto.

A desinfecção por ozônio com $0,04 \mathrm{mg} / \mathrm{L} \mathrm{O}_{3}$ foi a menos eficiente entre as utilizadas $73,28 \%$ e além disso não possui uma relação custo-benefício boa. A desinfecção por Cloro, que é a realizada pela ETAR, apresentou uma boa porcentagem 


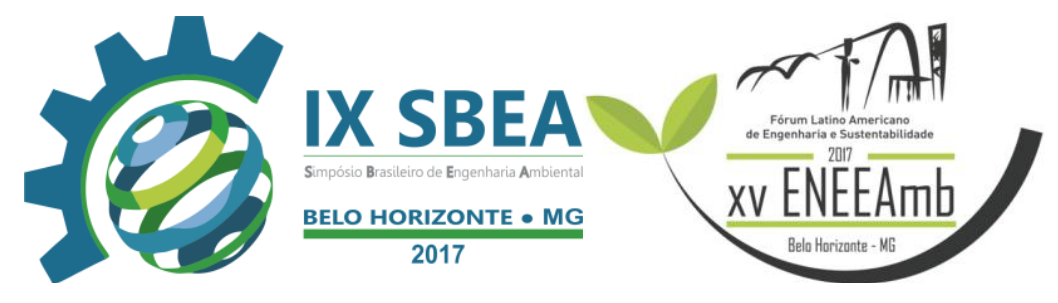

de remoção 99,99\% com uma dosagem de $20 \mathrm{mg} / \mathrm{L}$ de $\mathrm{Cl}_{2}$ e um tempo de desinfecção de 20 minutos se mostrando a mais adequada, pois se comparada com o UV a coloração do efluente não interfere no seu processo de desinfecção e essa possui melhor custo benefício que as demais.

Os três processos de desinfecção cumpriam com a legislação tanto portuguesa quanto brasileira, uma vez que as amostras somente apresentaram CT, não existindo CF e consequentemente E.coli, estando assim dentro dos padrões de lançamento.

Como recomendações, seria ideal que o tempo de desinfecção tanto para o UV quanto para o Ozônio fosse equivalente ao tempo de desinfecção do cloro efetuado na ETAR, recomenda-se fazer ensaios com diferentes doses de ozônio e também diferentes tipos de lâmpadas UV e na desinfecção por ozônio seria mais eficiente aumentar a coluna do reator e diminuir o tamanho das bolhas.

\section{REFERÊNCIAS BIBLIOGRÁFICAS}

JORDÃO, Eduardo Pacheco; PESSÔA, Constantino Arruda. Tratamento de esgotos domésticos. 5.ed. Rio de Janeiro: ABES, 2009.

LAPOLLI, Flávio Rubens et al .Desinfecção de efluentes sanitários através de dióxido de cloro. Eng. Sanit. Ambient., Rio de Janeiro , v. 10, n. 3, p. 200-208, Sept. 2005 .

METCALF, L.; EDDY, H. P. Wastewater engineering: treatment and reuse.4th ed. Boston: McGraw-Hill, 2004.

SPERLING.M.V.; Introdução a qualidade das águas e ao tratamento de esgotos, Ed.: Departamento de Engenharia Sanitária e Ambiental; Universidade Federal de Mina Gerais, Belo Horizonte;2005; vol. 1.

SPERLING, M. V. Princípios do tratamento biológico de águas residuárias. Belo Horizonte: UFMG, 2005. p. 36-37. 